\title{
Confounding Factors on the Comparison of Diclofenac Versus Ketoprofen as a Transdermal Drug Delivery System
}

\author{
Anas Ibrahim-Hamdan ${ }^{1}$
}

Received: 24 January 2019/Accepted: 31 January 2019/Published online: 8 February 2019

(c) The Association of Oral and Maxillofacial Surgeons of India 2019

To the Editor:

I read with great interest the article by Jadhav and colleagues in a recent issue of the journal [1]. The authors conducted a randomized clinical trial involving 50 patients undergoing maxillofacial surgery and concluded that ketoprofen transdermal patch was slightly better than diclofenac transdermal patch with respect to analgesic efficacy. The authors should be applauded for performing a well-designed study in an important topic (e.g., acute pain) in patients undergoing elective surgery $[2,3]$. The need to improve postoperative recovery by reducing moderate/severe postoperative pain makes the topic very important in maxillofacial surgery $[4,5]$.

Although the study of Jadhav et al. was well designed, there are some critical points that need to be clarified by the authors to determine the validity of their findings. First, it is unclear if the intraoperative and postoperative analgesic requirements were standardized for the study groups as this is important as it can affect the main outcome. Second, the authors performed multiple comparisons, but did not adjust their analysis to avoid a Type I error. Finally, it is unclear who collected the data regarding postoperative pain scores. The collection of pain scores performed by clinical nurses has been shown to be biased for analgesic studies, and this may have contributed for additional biases in the study results [6].

Anas Ibrahim-Hamdan

aibrahimhamdan@lifespan.org

1 Department of Anesthesiology, Rhode Island Hospital, The Warren Alpert Medical School of Brown University, 593 Eddy Street, Providence, RI 02903, USA
I would welcome some comments by the authors as this would help to further support the findings of this important study.

\section{Compliance with Ethical Standards}

Conflict of interest The author has no conflict of interest.

\section{References}

1. Jadhav P, Sinha R, Uppada UK, Tiwari PK, Subramanya Kumar AVSS (2018) Pre-emptive diclofenac versus ketoprofen as a transdermal drug delivery system: how they face. J Maxillofac Oral Surg 17:488-494

2. Yenidünya O, Bircan HY, Altun D, Caymaz I, Demirag A, Turkoz A (2017) Anesthesia management with ultrasound-guided thoracic paravertebral block for donor nephrectomy: a prospective randomized study. J Clin Anesth 37:1-6

3. Bansal V, Kumar D, Mowar A, Bansal A (2018) Comparison of Ropivacaine $0.75 \%$ and Lignocaine $2 \%$ with 1:200,000 adrenaline in dental extractions: Single Blind Clinical Trial. J Maxillofac Oral Surg 17:201-206

4. Kitlı A, Erdogan MA, Ozgul U, Aydogan MS, Ucar M, Toprak HI, Colak C, Durmus M (2017) Ultrasound-guided transversus abdominis plane block for postoperative analgesia in living liver donors: a prospective, randomized, double-blinded clinical trial. J Clin Anesth 37:103-107

5. Ueshima H, Hara E, Otake H (2017) Lumbar vertebra surgery performed with a bilateral retrolaminar block. J Clin Anesth 37:114

6. McCarthy RJ, De Oliveira GS (2015) The trouble with using provider assessments for rating clinical performance: it's a matter of bias. Anesth Analg 120:714-716

Publisher's Note Springer Nature remains neutral with regard to jurisdictional claims in published maps and institutional affiliations. 